\title{
Water Desalination Using Renewable Energy in a Humidification-Dehumidification Cycle for Bahrain Climate Conditions
}

\section{Omar Al-Abbasi}

Department of Mechanical Engineering, University of Bahrain, Isa Town, Kingdom of Bahrain

\section{Abstract}

Water desalination using humidification-dehumidification $(\mathrm{HDH})$ cycle has gained an increasing attention by several researchers recently. In this study, the humidificationdehumidification cycle that consists of solar air heater, solar air humidifier and condenser is studied numerically. In this cycle, air stream is first heated in the air solar heater to increase its temperature and decrease its relative humidity that allows it to

Corresponding Author: Omar Al-Abbasi omabbasi@uob.edu.bh Received: 18 September 2018 Accepted: 10 October 2018 Published: 15 October 2018

Publishing services provided by Knowledge $\mathrm{E}$

(c) Omar Al-Abbasi. This article is distributed under the terms of the Creative Commons

Attribution License, which permits unrestricted use and redistribution provided that the original author and source are credited.

Selection and Peer-review under the responsibility of the Sustainability and Resilience Conference Committee.

\section{G OPEN ACCESS} absorb more water moisture. The stream then enters the solar humidifier, in order to get humidified with the aim to reach saturation conditions. Finally, the water moisture carried by air stream is condensed in the condenser. A mathematical model coupling mass, momentum and energy balances is developed for each component. The fresh water production is estimated for HDH cycle based on Bahrain climate conditions. Key parameters affecting the rate of fresh water production was investigated. The investigated parameters are height of humidifier channel and height of water bed in the humidifier.

Keywords: Solar Desalination, Humidification-Dehumidification Cycle, Numerical Analysis, CFD

\section{Introduction}

Humidification-Dehumidification ( $\mathrm{HDH}$ ) is considered as one of simplest methods of desalinating water using the thermal energy [1]. This system has several virtues among them is simplicity of design and maintenance, low temperature operation and the ability to use renewable energy source to run the cycle. The last feature makes $\mathrm{HDH}$ an excellent technology for sustainable water desalination. Several researcher had investigated the use of $\mathrm{HDH}$ in water desalination [2]-[4]. The irreversibility of $\mathrm{HDH}$ systems had been investigated by Mistry et al. [5], and Lawal et al. [6]. Another bulk of the work on this topic has been dedicated to decrease the size of the dehumidifier 
in the $\mathrm{HDH}$ systems [7], [8]. For a comprehensive review about $\mathrm{HDH}$, the reader is advised to refer to the work of A. Giwa et al. [9]

\section{System Description}

The HDH system consists of three main parts, heater, humidifier and condenser. In the current study, a solar air heater represents the first part of the cycle, where the air gets heated using the thermal energy to increase its ability to carry water vapor. Air passes in a cross section of $1 \mathrm{~m} \times 0.05 \mathrm{~m}$ with a fixed inlet velocity of $1.5 \mathrm{~m} / \mathrm{s}$ in the air solar heater which has a length of $2.4 \mathrm{~m}$.

The second part of the system is a solar humidifier, where the solar irradiation heats both the air stream as well as the water bed in order to increase the amount of evaporation. Different configurations are tested for this part, where the length is kept fixed to $1 \mathrm{~m}$ and the height of the air channel is varied from $0.5 \mathrm{~cm}$ to $5 \mathrm{~cm}$. Similarly, the height of water bed is varied as well from $1 \mathrm{~cm}$ to $5 \mathrm{~cm}$. These different layouts are examined to study the performance of the system.

The final piece of the cycle is the condenser where sea water is assumed to be the cooling medium to condense the water vapor that was carried in the humidifier. $A$ layout depiction of the system is shown in Figure 1.

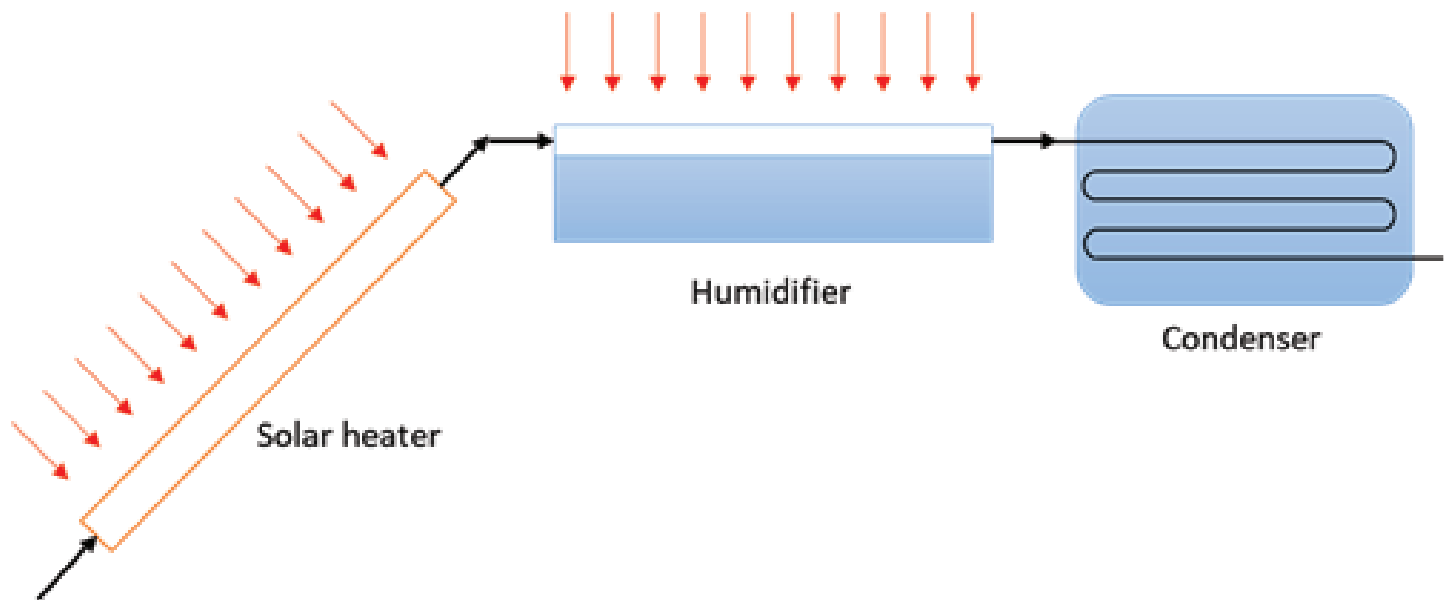

Figure 1: Schematic for considered humidification-dehumidification system.

\section{Mathematical Model}

Several physics are coupled to describe the system, these physics are mass, momentum and energy balances in addition to the transport of diluted species. For the current problem, the following assumptions are made: 
- Flow is incompressible and laminar

- Air behaves as an ideal gas

- Height of water bed in the humidifier is always constant, i.e., all the amount evaporated will be compensated by continuous feed

- The temperature of the coolant in the condenser is maintained at $20^{\circ} \mathrm{C}$

The mass balance of fluid field is given as follows:

$$
\frac{d \rho}{d t}+\rho \nabla \cdot u=0
$$

where $\rho$ is the density, $u$ the velocity vector in both $x$ and $y$ directions. The momentum balance in the flow domain is given as follows:

$$
\rho\left(\frac{\partial u}{\partial t}+u \cdot \nabla u\right)=-\nabla p+\nabla \cdot\left(\mu\left(\nabla u+(\nabla u)^{T}\right)-\frac{2}{3} \mu(\nabla \cdot u)\right)
$$

where $\mu$ is dynamic viscosity and $p$ is pressure. The energy balance is written as follows:

$$
\rho C p \frac{\partial T}{\partial t}+\rho C_{p} u \cdot \nabla T+\nabla \cdot(-k \nabla T)=Q
$$

where $k$ is thermal conductivity, $C p$ is specific heat, $T$ is temperature, and $Q$ is heat source. The transport of diluted species which accounts for the mass transfer of water vapor is expressed as follows:

$$
\frac{\partial c}{\partial t}+u \cdot \nabla c+\nabla \cdot(-D \nabla c)=0
$$

where $c$ is concentration of water vapor and $D$ is diffusion coefficient.

\section{Numerical Implementation}

The nonlinear partial differential equations expressed in equations (1)-(4) are solved using COMSOL Multiphysics [10]. The transient problem is solved using backward differentiation scheme with adaptive time stepping to advance the solution in time and segregated solver with variable damping factor are used to solve the coupled nonlinear equations. PARDISO algorithm with a relative tolerance equal to $1 \times 10^{-3}$ is used to solve the linearized systems.

\section{Results and Discussion}

The results presented in this section were obtained for Bahrain climate conditions and in particular for the first of August from 6 am until 6 pm. This choice was made to consider the amount of water production at its the peak demand throughout the year. 
The temperature profile for the solar humidifier at noon conditions is shown in Figure 2. This solution is picked for the case where the air channel and the water bed heights are both $3 \mathrm{~cm}$. It should be noticed that the solution is stretched in the $y$-axis several times in order to make the figure more readable. The solution shows that the air stream entering the solar humidifier is being heated from the top, where the solar irradiation is striking. The average temperature of the water bed at this specific time is $45^{\circ} \mathrm{C}$. The amount of evaporation in the humidifier is directly proportional to the temperature water bed. Thus, it is important to find the optimum configuration in order to maximums the amount of evaporation.

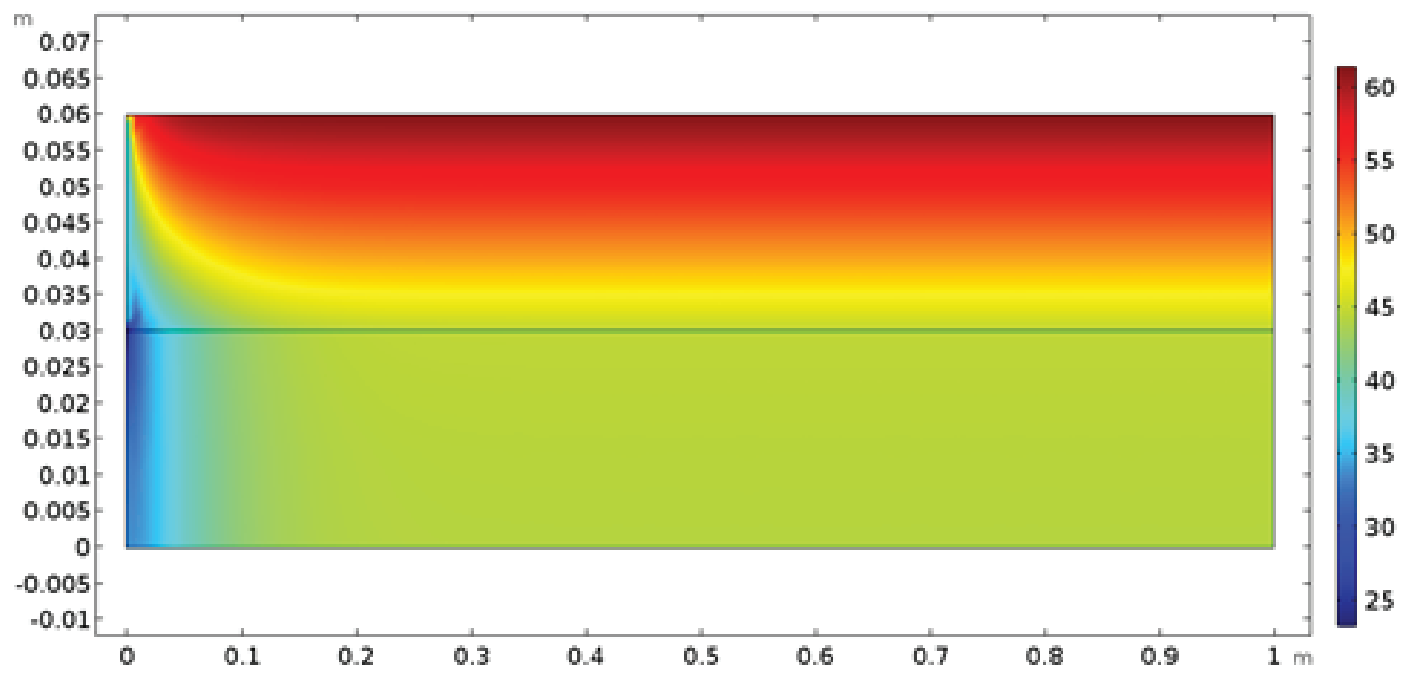

Figure 2: Temperature profile for the humidifier at $12 \mathrm{pm}$.

As mentioned earlier, two parameters are altered in this study, the heights of air and water channels. First, the influence of changing the height of the water channel is examined while fixing the height of the air channel. Figure 3 shows the average absolute humidity $(\omega)$ for the air stream as it exits the solar humidifier. The water channel of a height of $1 \mathrm{~cm}$, resulted at the minimum amount of $\omega$, while the maximum humidification effect is experienced at a height of $3 \mathrm{~cm}$ and not $5 \mathrm{~cm}$. This result is clearly showing that $\omega$ is not linearly proportional to the height of the water channel and there exists an optimum value at that range.

After investigating the effect of changing the height of the water bed, the effect of varying the height of the air channel while fixing the water channel is examined. Figure 4 shows $\omega$ at the exit of humidifier when the water channel is constrained to $3 \mathrm{~cm}$. These results show that the performance of the system is increasing, i.e., increasing $\omega$, by decreasing the height of the air channel, i.e., the relation between air channel and $\omega$ is monotonic and inversely proportional. 


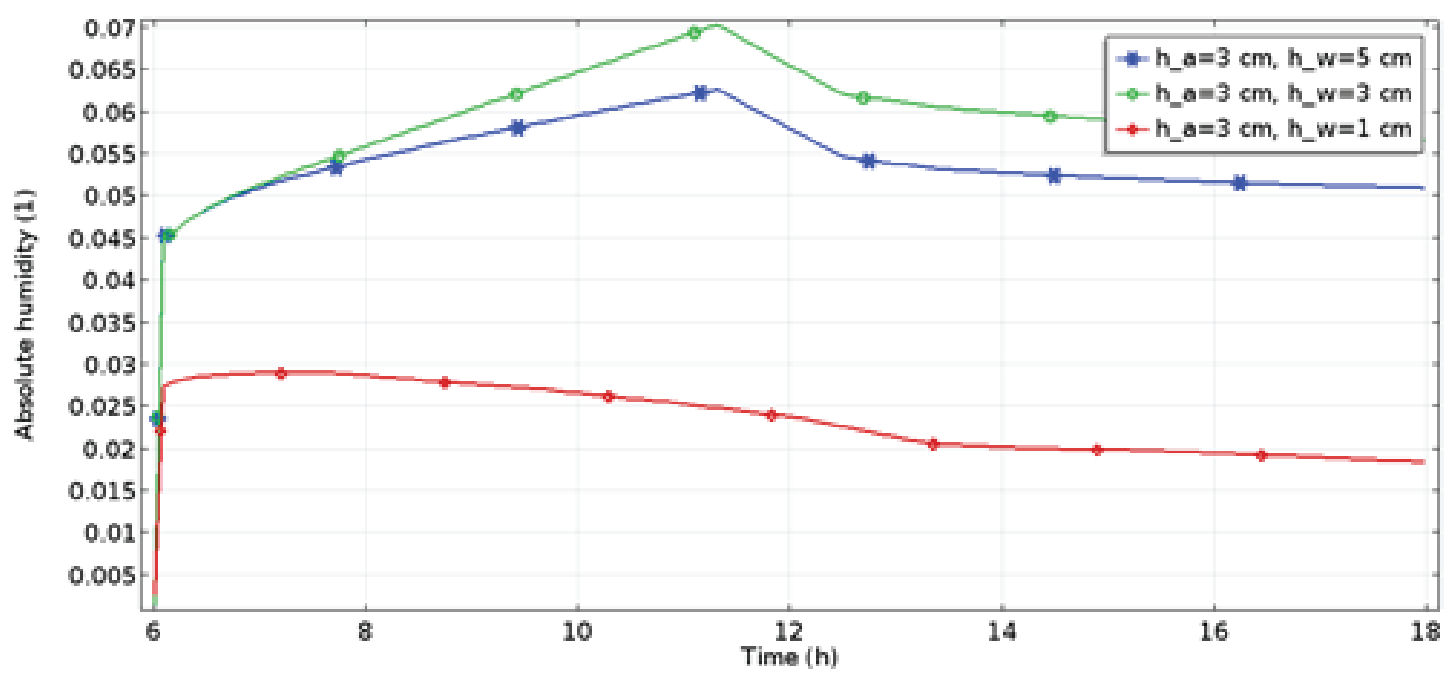

Figure 3: Absolute humidity of air after the humidifier section for different heights of water bed.

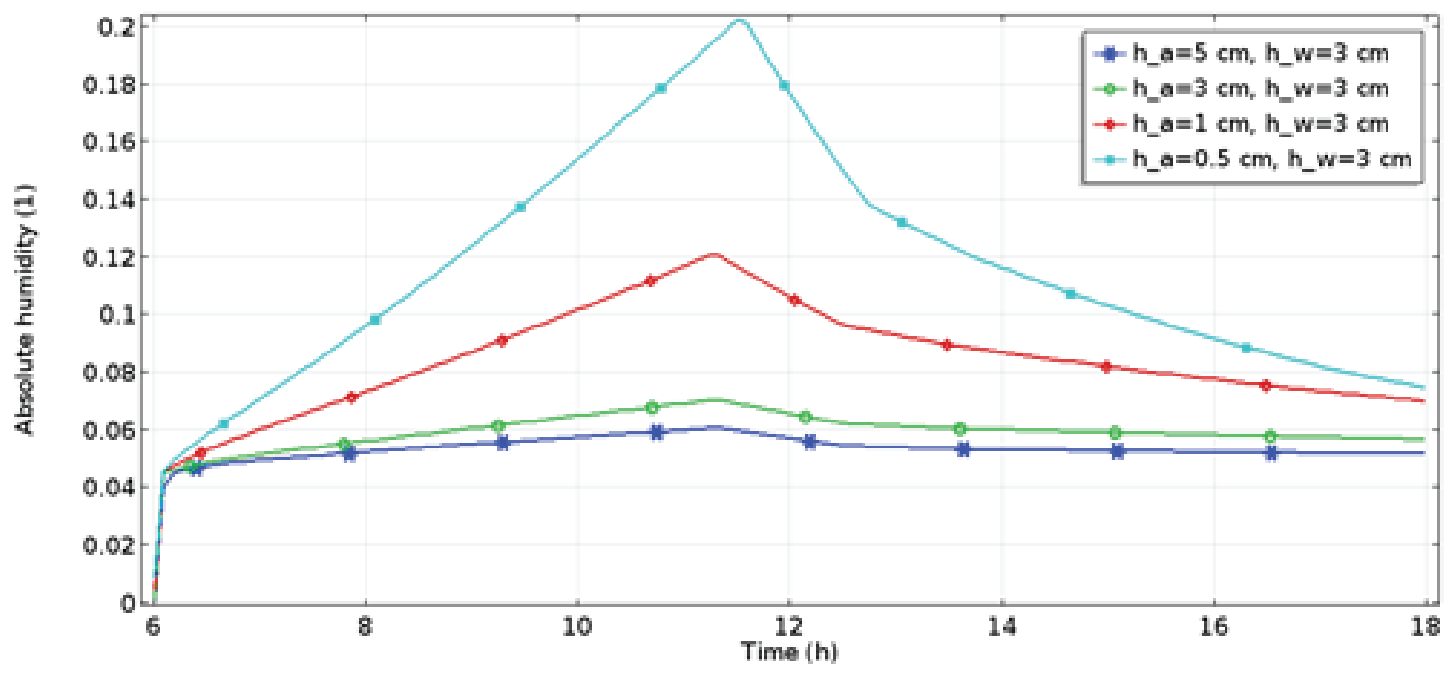

Figure 4: Absolute humidity of air after the humidifier section for different heights of air channels.

Figure 5 shows $\omega$ for all height combinations of air and water channels. As expected from the previous two figures, the maximum humidification is obtained for the heights of 0.5 and $3 \mathrm{~cm}$ for air and water channels, respectively. Decreasing the height of air channel had a significant increase on the performance of the system and made the solution more sensitive to the ambient conditions. The highest humidification is occurring around noon time, when the solar irradiation is in its peak.

The instantaneous amount of condensation in the condenser is shown in Figure 6. The trend in this figure is very close to the solution in Figure 5, since the temperature of the coolant is assumed to be at fixed temperature and the only variable controlling the amount of condensation is $\omega$. For the early period of the day until around 8:30 am, the smallest channel heights, i.e., $0.5 \mathrm{~cm}$ for air and $1 \mathrm{~cm}$ for water, produced the 


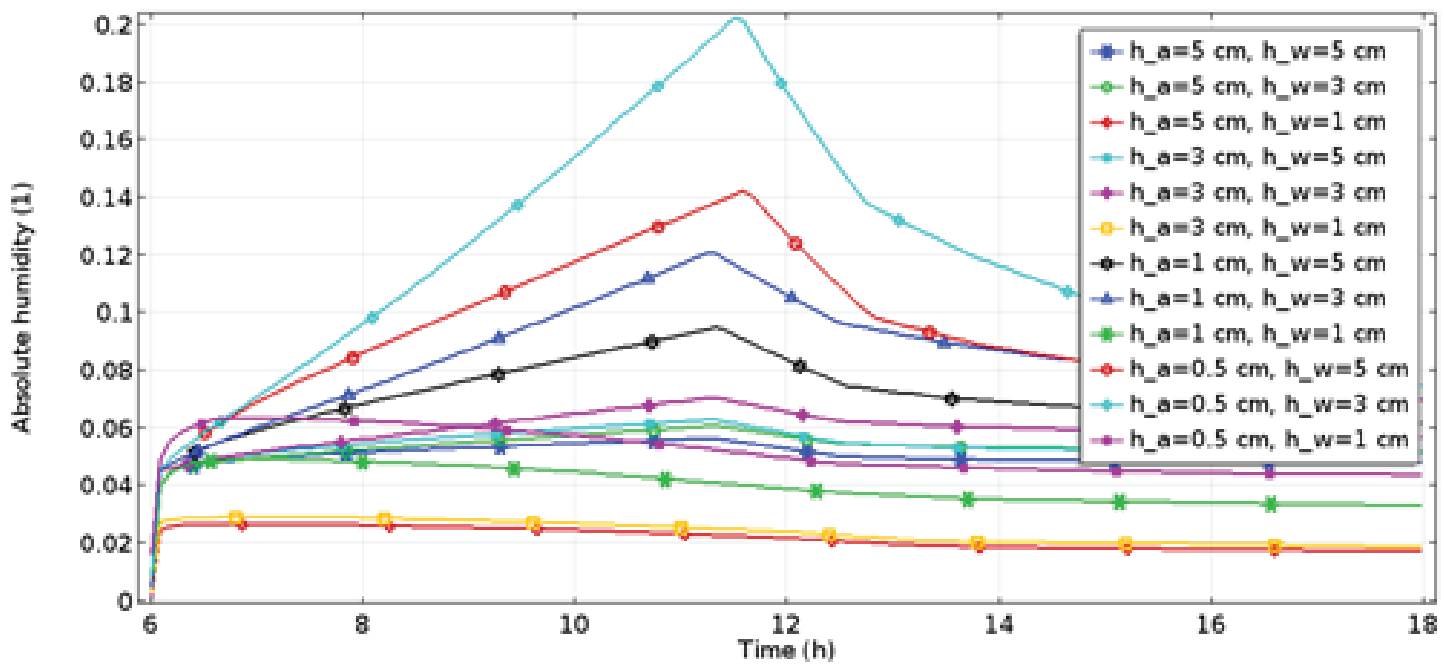

Figure 5: Absolute humidity of air after the humidifier section for all combinations of heights of the humidifier's water bed and air channel.

largest amount of condensate. Later in the day, increasing the height of water channel to $3 \mathrm{~cm}$, significantly increase the amount of condensate.

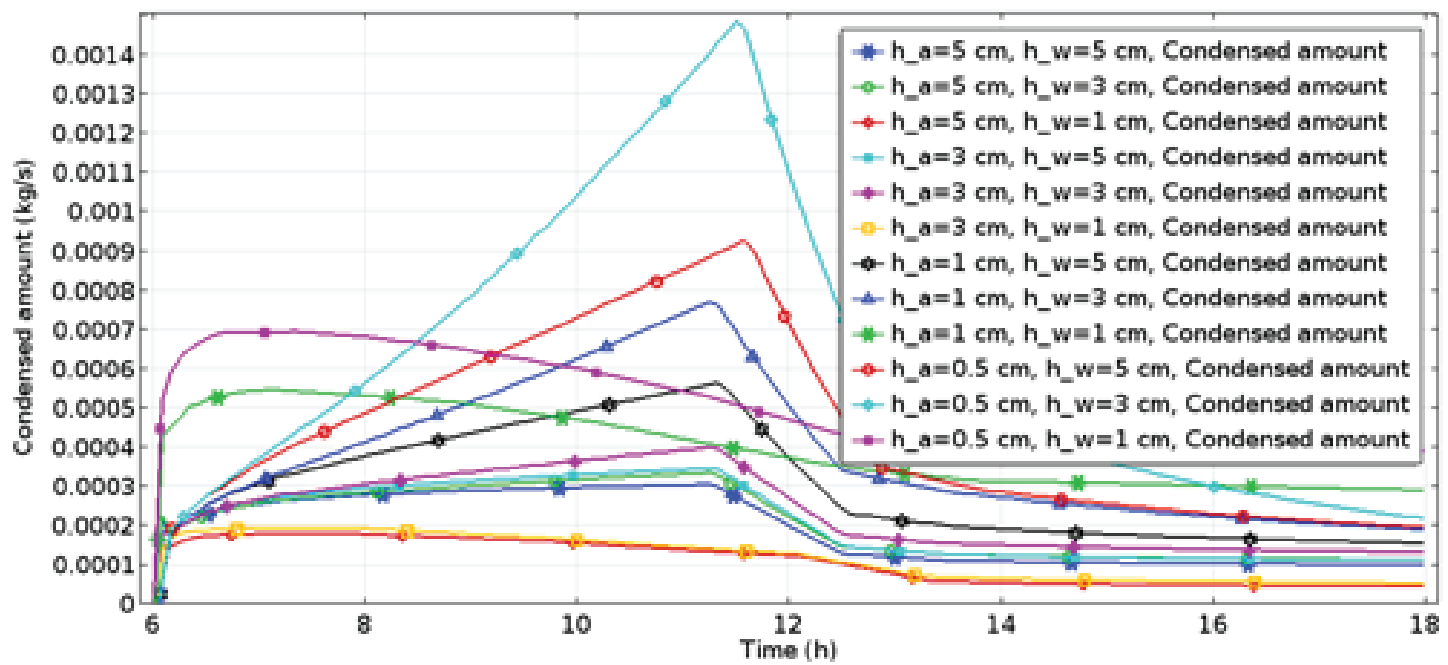

Figure 6: Condensed amount of water for the different configurations of humidifier.

The daily water production using the considered HDH system is presented in Table 1 , where the production varied from 4.5 to 26.3 L/day. Decreasing the air and water channels have very noticeable effect on the water production, therefore, these parameters need to be properly optimized in order to maximize the performance of the HDH cycle.

\section{Conclusions}

The performance of the HDH cycle is examined for Bahrain climate conditions in the summer season. Two key parameters that influence the amount of water production, 
TABLE 1: Daily condensed amount of fresh water for the different configurations of the humidifier.

Configuration
$h_{a}=5 \mathrm{~cm}, h_{w}=5 \mathrm{~cm}$
$h_{a}=5 \mathrm{~cm}, h_{w}=3 \mathrm{~cm}$
$h_{a}=5 \mathrm{~cm}, h_{w}=1 \mathrm{~cm}$
$h_{a}=3 \mathrm{~cm}, h_{w}=5 \mathrm{~cm}$
$h_{a}=3 \mathrm{~cm}, h_{w}=3 \mathrm{~cm}$
$h_{a}=3 \mathrm{~cm}, h_{w}=1 \mathrm{~cm}$
$h_{a}=1 \mathrm{~cm}, h_{w}=5 \mathrm{~cm}$
$h_{a}=1 \mathrm{~cm}, h_{w}=3 \mathrm{~cm}$
$h_{a}=1 \mathrm{~cm}, h_{w}=1 \mathrm{~cm}$
$h_{a}=0.5 \mathrm{~cm}, h_{w}=5 \mathrm{~cm}$
$h_{a}=0.5 \mathrm{~cm}, h_{w}=3 \mathrm{~cm}$
$h_{a}=0.5 \mathrm{~cm}, h_{w}=1 \mathrm{~cm}$

\begin{tabular}{|c|}
$\begin{array}{c}\text { Daily condensation amount } \\
(\text { L/day })\end{array}$ \\
8.1 \\
8.7 \\
4.5 \\
8.9 \\
10.0 \\
\hline 5.0 \\
12.8 \\
16.2 \\
16.9 \\
18.8 \\
26.3 \\
21.8
\end{tabular}

namely humidifier's air and water channels heights are examined. The results show that water production is inversely proportional to height of air channel, while an optimum height of the water bed exist for the specific operating conditions. Also, maximizing the water production can be achieved by having variable height of water channel, where it is minimum at the early mornings then it gets increased to an optimized value. The maximum water production is obtained for the case of 0.5 and $3 \mathrm{~cm}$ of air and water channels, respectively.

\section{References}

[1] A. S. Abdullah, F. A. Essa, Z. M. Omara, and M. A. Bek, "Performance evaluation of a humidification-dehumidification unit integrated with wick solar stills under different operating conditions," Desalination, vol. 441, pp. 52-61, Sep. 2018.

[2] G. Prakash Narayan, M. H. Sharqawy, E. K. Summers, J. H. Lienhard, S. M. Zubair, and M. A. Antar, "The potential of solar-driven humidificationâ $€$ "dehumidification desalination for small-scale decentralized water production," Renew. Sustain. Energy Rev., vol. 14, pp. 1187-1201.

[3] K. Bourouni, M. T. Chaibi, and L. Tadrist, "Water desalination by humidification and dehumidification of air: State of the art," Desalination, vol. 137, no. 1-3, pp. 167-176, May 2001.

[4] J. Moumouh, M. Tahiri, M. Salouhi, and L. Balli, "Theoretical and experimental study of a solar desalination unit based on humidification-dehumidification of air," Int. J. 
Hydrogen Energy, vol. 41, no. 45, pp. 20818-20822, Dec. 2016.

[5] K. Mistry, S. Z.-I. J. of T. Sciences, and undefined 2010, "Effect of entropy generation on the performance of humidification-dehumidification desalination cycles," Elsevier.

[6] D. U. Lawal, S. M. Zubair, and M. A. Antar, "Exergo-economic analysis of humidification-dehumidification (HDH) desalination systems driven by heat pump (HP)," Desalination, vol. 443, pp. 11-25, Oct. 2018.

[7] B. Dawoud, Y. H. Zurigat, B. Klitzing, T. Aldoss, and G. Theodoridis, "On the possible techniques to cool the condenser of seawater greenhouses," Desalination, vol. 195, no. 1-3, Pp. 119-140, Aug. 2006.

[8] 0. P. Agboola and F. Egelioglu, "An empirical evaluation of an integrated inclined solar water desalination system with spray jets variation," Desalin. Water Treat., vol. 53, no. 11, pp. 2875-2881, Mar. 2015.

[9] A. Giwa, N. Akther, A. Al Housani, S. Haris, and S. W. Hasan, "Recent advances in humidification dehumidification $(\mathrm{HDH})$ desalination processes: Improved designs and productivity," Renewable and Sustainable Energy Reviews, vol. 57. pp. 929944, 2016.

[10] "COMSOL Multiphysics ${ }^{\circledR}$ v. 5.2. www.comsol.com. COMSOL AB, Stockholm, Sweden.". 